\title{
Wind Driven Reverse Osmosis Desalination for Concrete Factory Application in Kuwait
}

\author{
A. A. Alsairafi and M. H. Al-Shehaima
}

\begin{abstract}
For decades, brackish and seawater desalination has been a solution for the shortage of fresh water, mostly in arid areas. However, desalination is an energy intensive technology and its energy cost stays very high even in countries producing fossil fuels, as in the case of Kuwait. The consumption of water per capita is very high in Kuwait, at 500 liters per person per day, due to the long summer season with high temperature that easily exceeds $45^{\circ} \mathrm{C}$. Interest in generating fresh water in Kuwait using a renewable energy has been grown in the last few years. In this work, a comparative study in terms of evaluating electric energy potential that could be generated to operate a Reverse Osmosis (RO) desalination unit is presented. This energy will then feed a concrete factory in Al-Taweel station located South of Kuwait city. In order to perform the required calculations, a computer program will be developed. The wind data will be used to predict the potential wind energy at different heights. The monthly average wind speed for the considered site is approximately $5 \mathrm{~m} / \mathrm{s}$ at a standard height of 10 m. The power-law method will be used to extrapolate the wind data at different heights. The nominal production potential of the RO system will then be estimated.
\end{abstract}

Index Terms-Reverse osmosis, wind energy, fossil fuels, wind turbine.

\section{INTRODUCTION}

Wind energy is the form of kinetic energy associated with the ambient air movement which can be converted to power. Since wind power is a renewable energy, it is considered as a better option instead of traditional fossil fuels energy resources. This clean form of energy has been in use since ancient times for sailing, milling grains and for pumping the needed water for irrigation. One of the main advantages of wind energy is that it has no damaging effect on the environment and large scale wind energy systems have the potential to greatly reduce global warming and climate change effects on the earth. In addition, it can greatly reduce pollution that occurs in many other forms such as acidic rain, smog and haze.

The overall available wind power surrounding the world is about 1011 Gigawatts [1]. It is expected in the future that the wind energy will be the most cost effective source of electricity, because of its advantage of generating electricity without producing carbon emission [2]. The cost of wind energy is declining while other power technologies are becoming more expensive. The capital cost of wind turbine

Manuscript received December 9, 2014; revised May 20, 2015.

A. A. Alsairafi and M. H. Al-Shehaima are with the Department of Mechanical Engineering, College of Engineering and Petroleum, Kuwait University, P.O. Box 5969, Safat 13060, Kuwait (e-mail: ammar.alsairafi@ku.edu.kw, m_alshehaima@hotmail.com). project is ranged between $75 \%$ and $90 \%$ of the total cost. Once the project has been commissioned, the only expenses left are for maintenance and operation [3]. The best location for a wind farm depends on several factors such as the wind speed, the generator type, the wind energy and a feasibility study [4]. The wind speed can be fixed or variable, but a research proved that more energy can be obtained from the variable speed [5].

Kuwait is one of the oil producing countries where large amount of this oil is consumed by refineries, power plants and petroleum and petrochemical industries. The first windmill in Kuwait, known as Ben Shlash windmill, was installed in the beginning of 1900s which is about $70 \mathrm{~km}$ Northwest of Kuwait city. From that time there is no practical use of wind energy in Kuwait. According to the Kuwaiti Ministry of Electricity and Water, the demand of electrical power in Kuwait was increased during the last years from $4120 \mathrm{MW}$ in 1993 to $14,256 \mathrm{MW}$ in 2014. The main electrical consumption of power in Kuwait is for air conditioning several buildings such as schools, houses, offices and shopping centers, especially in summer season.

A desalination plant requires a constant supply of either electricity or thermal energy source such as a fossil fuel. The use of the renewable energy resource such wind is good if the supply of fossil fuel is expensive or insecure. On the other hand, the wind turbines are known by their high capital cost compared with Reverse Osmosis (RO) systems powered by electricity or thermal energy. For this reason, the RO membranes should provide excellent energy efficiency in order to make the system economically viable [6]. During the hours of day time, the batteries are charged to allow operation of RO system at constant flow. Unfortunately, the batteries have short life especially in hot climates and the efficiency of the batteries reduces as they age, which mean reduction of product water flow.

Several desalination technologies for the utilization of desalinated brackish water in Jordan were evaluated [7]. The evaluation of various desalination technologies was carried out using multi-criteria analysis based on technical, economic, and environmental aspects of both quantity and quality of the brackish waters. The results revealed that reverse osmosis (RO) technology followed by electrodialysis (ED) are ranked among the most appropriate.

A small-scale seawater reverse-osmosis system powered by wind energy without batteries was investigated [8]. Their system comprises $2.2 \mathrm{~kW}$ wind turbine generator powering a variable-flow Reverse osmosis (RO) desalination unit, which is highly efficient and suitable for use in remote areas. Variable flow operation permits the variable range of the wind speed to be accommodated without need of energy 
storage. Hence batteries which are common in stand-alone systems are avoided and water production is dependent on the instantaneous wind speed. They concluded that their proposed configuration can be a promising alternative for the desalination of seawater to communities on isolated inland areas.

Wind characteristics in the state of Kuwait for six different locations were evaluated [9]. The researchers reported that the annual average wind speed for the considered sites ranged from 3.7 to $5.5 \mathrm{~m} / \mathrm{s}$ and a mean wind power density from 80 to $167 \mathrm{~W} / \mathrm{m} 2$ at standard height of $10 \mathrm{~m}$. The wind data at different heights of $15,20,25$ and $30 \mathrm{~m}$ were extrapolated from the $10 \mathrm{~m}$ data using the power law. They also found that maximum power density is obtained at $30 \mathrm{~m}$ height which varies between 130 and $275 \mathrm{~W} / \mathrm{m} 2$. In addition, the highest potential wind power was found during the summer season which is the peak demand season for electricity in Kuwait.

A small-scale seawater reverse-osmosis system with high energy efficiency has been studied [6]. The production of potable water was up to $460 \mathrm{~L} / \mathrm{h}$ from seawater at $40,000 \mathrm{ppm}$ with electrical power consumption is less than $1600 \mathrm{~W}$ and specific energy consumption is less than $3.5 \mathrm{kWh} / \mathrm{m}^{3}$. The power consumption can be reduced by controlling the flow without any significant loss of efficiency. The advantage of their system is that it may be operated by renewable energy sources such as wind without the need of batteries.

The main objectives of this study can be stated as follows: (1) evaluate the potential wind energy in Al-Taweel station located to the south of Kuwait city; (2) use wind energy to operate a reverse osmosis plant that feed a concrete factory. The brackish water is supplied from huge well, around $150 \mathrm{~m}$ deep. The salinity of the brackish feed water is in the order of 8920.34 ppm.

\section{Wind SPEED DATA AND POWER CALCUlations}

The wind speed data, direction and frequency distribution at nine locations from 1998 to 2002 are used to analyze wind energy, as shown in Fig. 1. One of these nine locations, AL-Taweel station located in Chabd, is chosen for study in the current work. All available data in hourly time series format were analyzed at a height equal to $10 \mathrm{~m}$. This data is measured between January to May and September 2005, and this is the only data that is available. All wind speed data were recorded at a height of $10 \mathrm{~m}$. In addition to the continuously recorded wind speed data, temperature, relative humidity, pressure and several weather properties were also stored over 1 hour periods [10].

The wind speed near the ground changes with height. The most common expression that predicts the wind speed at one height in terms of the measured speed at another height is the power law which is given by:

$$
\frac{V_{2}}{V_{1}}=\left(\frac{h_{2}}{h_{1}}\right)^{m}
$$

where $V_{1}$ is the actual wind speed recorded at height $h_{1}$ and $V_{2}$ is the wind speed at the required or extrapolated height $h_{2}$.
The exponent $m$ depends on surface roughness and atmospheric stability. This constant varies from 0.1 to 0.4 with the most frequently adopted value being 0.14 [11]. A value of 0.14 is used in this work for low surface roughness and well exposed sited, which is the case of this study. The wind speed data were extrapolated based on the power law at $15,20,25,30$, and $78 \mathrm{~m}$ heights, respectively. The mean wind speed for the summer season months at height of $10 \mathrm{~m}$ is $5 \mathrm{~m} / \mathrm{s}$, which mean fair wind classification [9].

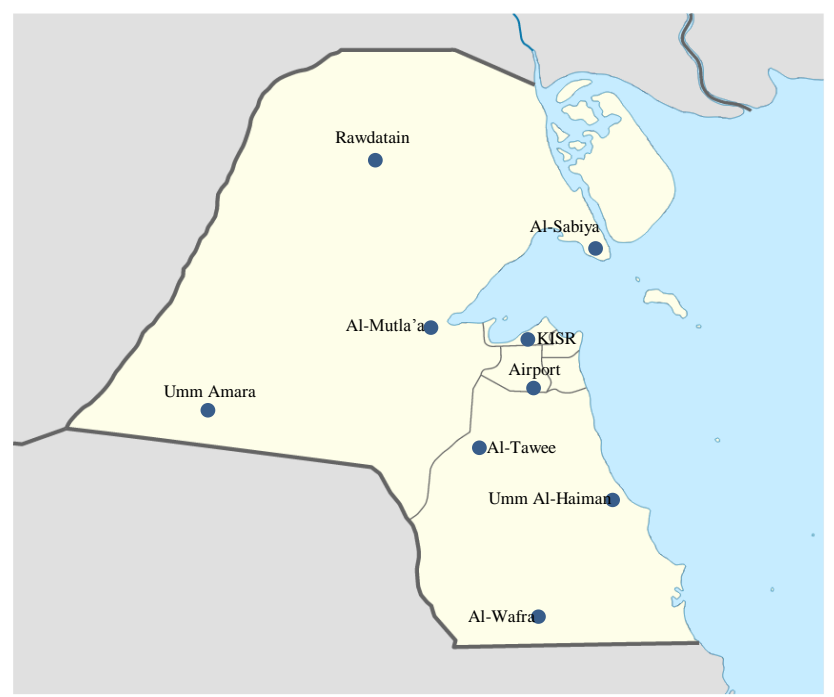

Fig. 1. Distribution of meteorological stations around Kuwait [12].

The energy available in a wind stream is a function of air density, the wind velocity, power coefficients and the area intercepting the wind, i.e., the area swept by wind machine blades. The wind power $P$ is given by:

$$
P=\frac{1}{2} \rho A_{t} C_{p} V^{3}
$$

where $\rho$ is the air density $\left(\mathrm{kg} / \mathrm{m}^{3}\right)$, At is the cross-sectional area of the wind turbine normal to the flow $\left(\mathrm{m}^{2}\right), V$ is the wind speed $(\mathrm{m} / \mathrm{s})$, and $C p$ is the power coefficients which depend on the construction type of the wind turbine. In this project, Enercon wind turbine [commercially called E82] is used which is called E82. The main reason for selecting this wind turbine is that it produces high power and is the only wind turbine that provides all the technical data that is required for the analysis. It has a rated power of $2000 \mathrm{~kW}$ with swept area of $5281 \mathrm{~m}^{2}$. The hub height is $78 \mathrm{~m}$, which is the minimum available height for this turbine. It should be noted that as the hub height of turbine increases, the error in extrapolating the wind speed at that height using the power law also increases.

The air density depends on the temperature, relative humidity, and air pressure and it was calculated using EES software with the metallurgical data input file. The power coefficients for all different heights were estimated using the curve-fitted equation obtained from the power coefficient curve available in the wind turbine catalog using Sigmaplot software. The well is classified as huge type with total production capacity of $60-80 \mathrm{~m}^{3} / \mathrm{h}$. Its depth is $120 \mathrm{~m}$ with a borehole of $12 \mathrm{in}$. The used screens inside the well work as water pre-filtration before it enters the feed tank. 


\section{MODELING BRACKISH WELl WATER REVERSE OSMOSIS}

Winflows 3.0 software is used in the design and analysis of the proposed RO system and the performance of membranes. The main input data of the model are the feed stream composition, water temperature, $\mathrm{PH}$, site density index, product flow rate and $\mathrm{RO}$ recovery. The number of pressure vessels and the elements' number in each pressure vessel were also specified. The selection of membrane element type depends on the type of water and its temperature. After setting all these requirements, the software provides a result summary which include RO feed, feed pressure, the need of chemical treatment process and any error in the RO design (if any).

To decide whether the wind turbine can run the plant, it is essentially required to know the operation scenario of it and to calculate the required energy per day. The submersible pump works for one hour to fill the feed tank. Once the tank is filled, the low pressure and high pressure pumps are turned on and the RO unit will start to operate.

Fig. 2 shows the plant schematic arrangement and components. The raw brackish water coming from the well flows into the feed tank by a submersible pump. It is then sent to a filtration stage by low pressure pump of horizontal type to overcome the pressure drop during water transportation. This water reaches the RO unit using a high pressure pump. The product water is stored in a swimming pool like tank (product water tank) which is below the ground level with cover to avoid falling of dust and birds inside it.

The suggested type of pump to draw the brackish water from its well is submersible pump located at $58 \mathrm{~m}$ inside the well. As shown in Fig. 2, there are four elbows of type regular 90 /threaded. The distance between the well and the tank is $2.5 \mathrm{~m}$ while the distance from the vertical pipe to the tank inlet is $0.5 \mathrm{~m}$. The material of the pipes is PVC plastic with diameter $0.0508 \mathrm{~m}$ ( 2 in). In order to choose the suitable pump, the head loss should be calculated.

The minor head losses in the system include elbow fittings which has loss coefficient $K=1.5$ and the tank entrance that has loss coefficient $K=1$. The minor head loss equation is:

$$
h_{\text {minor }}=\sum K \frac{Q^{2}}{2 g A^{2}}
$$

where $h_{\text {minor }}$ is the minor head loss, $K$ is loss coefficient, $Q$ is volumetric flow rate $\left(Q=40.38 \mathrm{~m}^{3} / \mathrm{hr}\right), g$ is the gravitational acceleration $\left(g=9.81 \mathrm{~m} / \mathrm{s}^{2}\right)$, and $A$ is pipe cross sectional area.

The major head loss is calculated by the following equation:

$$
h_{\text {major }}=f \frac{L}{D} \frac{Q^{2}}{2 g A^{2}}
$$

where $h_{\text {major }}$ is major head loss, $f$ is friction factor, $L$ is total length of horizontal pipes $(L=3 \mathrm{~m}), D$ is pipe diameter $(D=$ $0.0508 \mathrm{~m}$ ( $2 \mathrm{in})$ ). In order to calculate the friction factor $f$, the Reynolds number should be determined first using the following equation:

$$
\operatorname{Re}=\frac{\rho D Q}{\mu A}
$$

where Re is the Reynolds number, $\rho$ is the water density ( $\rho=$ $\left.995.7 \mathrm{~kg} / \mathrm{m}^{3}\right)$, and $\mu$ is dynamic viscosity $\left(\mu=7.975 \times 10^{-4}\right.$ N.s $/ \mathrm{m}^{2}$ ). The assumed plastic pipe roughness $\varepsilon=0$, then $\varepsilon / D=0$. Using Moody chart, the estimated friction factor $f=0.014$.

The vertical head loss is equal to the feed tank height $\left(L_{\text {tank }}\right.$ $=6.5 \mathrm{~m}$ ). Then, the total head loss is about $76.72 \mathrm{~m}$ and with $15 \%$ correction factor, the corrected head loss is about $88 \mathrm{~m}$. Checking the available catalog, the suitable pump is with a consumed power of $17.5 \mathrm{~kW}$.

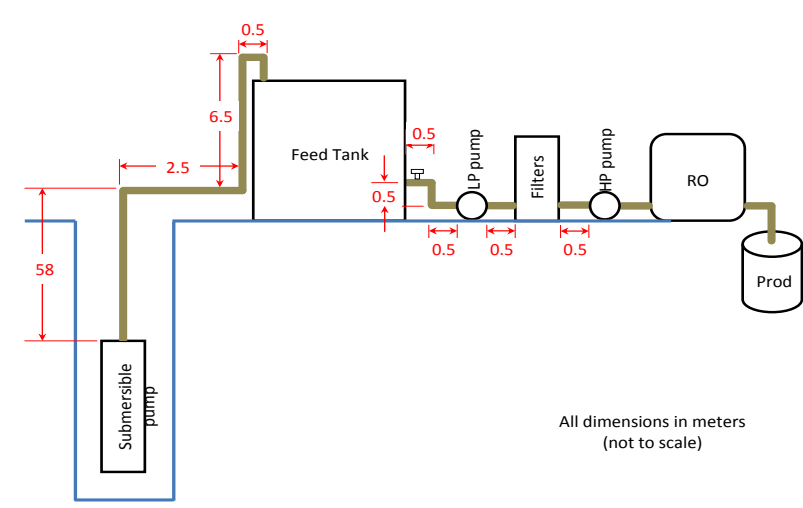

Fig. 2. Suggested Plant Layout.

For the low-pressure pump, the main head losses are due to major head losses, minor head losses, vertical head and pressure drop in filters, as shown in Fig. 2. The minor head losses can be estimated with the following assumed values: $K$ $=1.5$ (loss coefficient for each elbow), $K=10$ (loss coefficient for Globe fully open valve) and $K=0.5$ (loss coefficient for Tank exit). Then, $h_{\text {minor }}=21 \mathrm{~m}$. The vertical head loss is $0.5 \mathrm{~m}$ and the major head loss for a total horizontal pipe length of $2 \mathrm{~m}$ is about $0.86 \mathrm{~m}$. The maximum pressure drop in filters should not exceed 1 bar. If the pressure drop exceed this value the system should be shut down to clean the filters. The head loss in filters is found by:

$$
\text { Head loss in filters }=\frac{\Delta P}{\rho g}
$$

where $\Delta P$ is the pressure drop $\left(\Delta P=1 \times 10^{5} \mathrm{~Pa}\right)$. Then, the estimated head loss in filters is $10.2 \mathrm{~m}$ and the total head loss for the low pressure pump becomes $32.7 \mathrm{~m}$. This will require a pump with a consumed power of $11 \mathrm{~kW}$.

For the high-pressure pump selection, the feed pressure of the RO unit found from Winflows 3.0 software is 15.46 bar. The following equation is used to estimate the head loss across the pump:

$$
\text { Head loss of the pump }=\frac{\Delta P}{\rho g}
$$

Hence, the head loss of the pump is $158.2 \mathrm{~m}$ and the suitable pump has a consumed power of $30 \mathrm{~kW}$.

The water consumption for the concrete factory is approximately $109.2 \mathrm{~m}^{3} /$ day (750,000 Gallons/month). The 
working hours per day is 13 . The product tank size should be enough to feed the factory for one complete day to withstand emergency cases such as pump damage and/or maintenance. The chosen tank size is $5 \times 6 \times 4 \mathrm{~m}^{3}$ made from concrete below the ground level to avoid back pressure to the RO unit. Total calculated total amount of energy required for one day $=$ $\sum$ (\# of hrs for each pump $\times$ pump power $)=485.5 \mathrm{kWh}$.

\section{ELECTRICAL CONNECTIONS}

The electrical connection components between the wind turbine and the plant are shown in Fig. 3. These components include a rectifier, a battery bank, and an inverter. The rectifier converts the AC current produced by the wind turbine to DC current and stores it in the battery bank. Since the plant requires $\mathrm{AC}$ current, an inverter is installed to change the output DC current from the battery bank into AC current and then supplies it to the plant. The days of autonomy of the battery, which represent how many days the battery can run the plant without the need of the wind turbine, is assumed to be one day in the current work. The inverter efficiency is assumed to be $90 \%$. The depth of discharge of battery (DOD) is assumed to be $40 \%$. The minimum energy of the wind turbine over the six month period is $1762.509 \mathrm{kWh}$. The output energy of the electrical connection $=$ Inverter efficiency $\times$ DOD $\times$ minimum turbine energy $=0.9 \times 0.4 \times$ $1762.509=634.5 \mathrm{kWh}$. Clearly, this energy is greater than the amount of energy required to run the plant for one day, so the system is satisfactory.

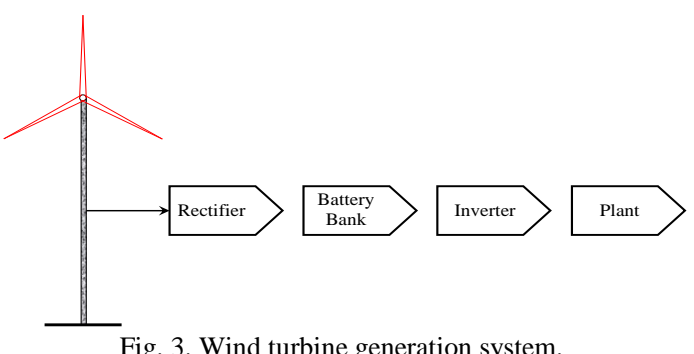

\section{CONCLUSIONS}

In this work, the wind data in AL-Taweel station - Kuwait were analyzed for the purpose of integrating wind energy with a reverse osmosis desalination system for a concrete factory application. The wind data from the Meteorological department climatological superintendency - Kuwait International Airport was used to predict the potential wind energy at different heights of $15,20,25,30$, and $78 \mathrm{~m}$, respectively. The mean wind speed was $5 \mathrm{~m} / \mathrm{s}$ at $10 \mathrm{~m}$ height. The ability to accurately estimate the wind speed and energy at different heights is important to effectively use this free source of energy. For the calculation procedure of the wind power, Enercon E82 wind turbine was selected. Winflows software is used for the performance predictions for the RO desalination system. Based on the calculated results, it was found that wind energy systems can be installed for producing both electricity and fresh water to feed a concrete factory in addition of replacing conventional energy systems. The nominal production potential of the RO system is found to be
$15.75 \mathrm{~m} 3 / \mathrm{hr}$ at $78 \mathrm{~m}$. Based on the RO calculations, the expected nominal power load for the operation of the RO desalination system is found to be $58.5 \mathrm{~kW}$ which is about one-fifth of the total potential of available wind energy.

\section{ACKNOWLEDGMENT}

The authors would like to thank Dr. Salim Alhajraf, the Executive Director of the Energy and Building Research Center at Kuwait Institute for Scientific Research.

\section{REFERENCES}

[1] N. P. Cheremisinoff, Fundamentals of Wind Energy, Ann Arbor, MI Ann Arbor Science Publisher Inc., 1979.

[2] A. Hepbasli and O. Ozgener, "A review on the development of wind energy in Turkey," Renewable and Sustainable Energy Reviews, vol. 8, issue 3, pp. 257-276, October 2003

[3] E. K. Akpinar and S. Akpinar, "An assessment on seasonal analysis of wind energy characteristics and wind turbine characteristics," Energy Conversion and Management, vol. 16, no. 11, pp. 1848-1867, 2004.

[4] E. K. Akpinar and S. Akpinar, "A statistical analysis of wind speed data used in installation of wind energy conversion systems," Energy Conversion and Management, vol. 46, no. 4, pp. 515-532, May 2004.

[5] V. Calderaro, V. G. Piccolo, and P. Siano, "A fuzzy controller for maximum energy extraction from variable speed wind power generation systems," Electric Power Systems Research, vol. 78, no. 6, pp. 1109-1118, September 2008.

[6] M. Thomson, M. Miranda, and D. Infield, "A small-scale seawater reverse-osmosis system with excellent energy efficiency over a wide operating range," Desalination, vol. 153, no. 1-3, pp. 229-236, 2002.

[7] M. Mohsen and O. Al-Jayyousi, "Brackish water desalination: an alternative for water supply enhansment in Jordan," Desalination, vol. 124, issue 1-3, pp. 163-174, November 1999.

[8] M. Miranda and D. Infield, "A wind-powered seawater reverse-osmosis system without batteries," Desalination, vol. 153, issue 1-3, pp. 9-16, April 2002.

[9] W. Al-Nassar, S. Alhajraf, and L. Al-Awadhi, "Potential wind power generation in the State of Kuwait," Renewable Energy, vol. 30, issue 14, pp. 2149-2161, January 2005.

[10] Personal Communication. Meteorological Department Climatological Superintendency, Kuwait International Airport.

[11] E. L. Petersen et al., "Wind power meteorology, Part I: Climate and turbulence," Wind Energy, vol. 1, pp. 25-45, April 1998.

[12] Personal Communication, Kuwait Institute for Scientific Research, the Energy and Building Research Center.

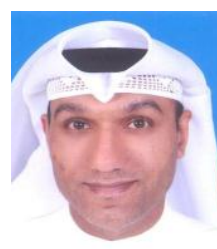

Ammar A. Alsairafi was born in Dasma, Kuwait, in 1971. He received the B.Sc. degree in mechanical engineering from Kuwait University, Kuwait, in 1995, the M.S. degree in mechanical engineering from the Ohio State University, Columbus Ohio, USA, in 1998 and $\mathrm{Ph} . \mathrm{D}$. degree in mechanical engineering from the Case Western Reserve University, Cleveland Ohio, USA, in 2003 .

In 2003, he joined the Department of Mechanical Engineering, Kuwait University, as an assistant professor and became an associate professor in 2014. His current research interests include CFD, renewable energy, combustion, fluid and heat transfer.

Dr. Alsairafi is a member of the American Society of Mechanical Engineers (ASME), the American Society of Heating, Refrigerating and Air Conditioning Engineers (ASHRAE), the American Society for Engineering Education (ASEE), and the Kuwait Society of Engineers (KSE). He is currently the Engineering Training \& Alumni Center director for the College of Engineering \& Petroleum, Kuwait University.

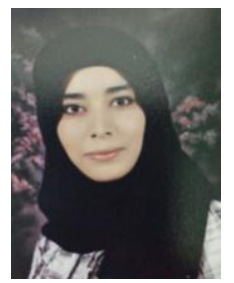

Mariam H. Al-Shehaima was born in Kuwait, in 1983. She received the B.Sc. and the M.S. degrees in mechanical engineering from Kuwait University, Kuwait, in 2006 and 2011, respectively. Since then, she has been with the Mechanical Engineering Department, Kuwait University, where she is currently a scientific assistant. 
Hydrogen Energy 
